\title{
Prevention of HIV and sexually transmitted diseases in high risk social networks of young Roma (Gypsy) men in Bulgaria: randomised controlled trial
}

\author{
Jeffrey A Kelly, Yuri A Amirkhanian, Elena Kabakchieva, Sylvia Vassileva, Timothy L McAuliffe, \\ Wayne J DiFranceisco, Radostina Antonova, Elena Petrova, Boyan Vassilev, Roman A Khoursine, \\ Borislav Dimitrov
}

Editorial by Valente

Center for AIDS Intervention Research (CAIR) Department of Psychiatry and Behavioral Medicine, Medical College of Wisconsin, 2071 North Summit Avenue, Milwaukee, Wisconsin 53202, USA

Jeffrey A Kelly professor of psychiatr and behavioural medicine

Yuri A

Amirkhanian

assistant professor of psychiatry and behavioural medicine

Timothy I McAuliffe professor of psychiatry and behavioural medicine and biostatistic

Wayne J

DiFranceisco senior research scientist

Municipal Hospital for Infectious

Diseases,

Mirgorodskaya 3, St

Petersburg 193167

Russia

Yuri A

Amirkhanian

assistant professor of psychiatry and

behavioural medicine

Roman A

sine

research associate

Health and Social

Development

Foundation, Sofi

1606, Bulgaria

Elena Kabakchieva

director and chair

Sylvia Vassileva

project coordinator

Radostina

Antonova

psychologist

Boyan Vassilev

psychologist

continued over

BMJ 2006;333:1098-101

\begin{abstract}
Objective To determine the effects of a behavioural intervention for prevention of HIV and sexually transmitted diseases that identified, trained, and engaged leaders of Roma (Gypsy) men's social networks to counsel their own network members. Design A two arm randomised controlled trial. Setting A disadvantaged, impoverished Roma settlement in Bulgaria.
\end{abstract}

Participants 286 Roma men from 52 social networks recruited in the community .

Intervention At baseline, all participants were assessed for HIV risk behaviour, tested and treated for sexually transmitted diseases, counselled in risk reduction, and randomised to intervention or control groups. Network leaders learnt how to counsel their social network members on risk prevention. Networks were followed up three and 12 months after the intervention to determine evidence of risk reduction. Main outcome measure Occurrence of unprotected intercourse during the three months before each assessment.

Results Reported prevalence of unprotected intercourse in the intervention group fell more than in control group (from $81 \%$ and $80 \%$, respectively, at baseline to $65 \%$ and $75 \%$ at three months and $71 \%$ and $86 \%$ at 12 months). Changes were more pronounced among men with casual partners. Effects remained strong at long term follow-up, consistent with changes in risk reduction norms in the social network. Other measures of risk reduction corroborated the intervention's effects.

Conclusions Endorsement and advice on HIV prevention from the leader of a social network produces well maintained change in the reported sexual practices in members of that network. This model has particular relevance for health interventions in populations such as Roma who may be distrustful of outsiders.

Trial registration Clinical Trials NCT00310973.

\section{Introduction}

The largest ethnic minority group in eastern Europe, the Roma, are also one of the region's most marginalised and disadvantaged populations. Roma first migrated from northern India in the 10th century and today constitute $6-9 \%$ of the populations of countries in south eastern Europe. ${ }^{1}$ Distinguishable by appearance, culture, and customs, Roma are no longer nomadic but usually live in settlements set apart from the majority community and characterised by poverty, overcrowded and dilapidated housing, poor sanitation, and few public health services. ${ }^{2}$ The circumstances of Roma in Bulgaria are typical of the region. Only $10 \%$ of Bulgarian Roma complete primary education, $80 \%$ are illiterate, unemployment rates are between $70 \%$ and $90 \%$, and most employed Roma do menial work for little money. ${ }^{3-5}$ Roma life expectancy is $10-15$ years shorter than that of the majority population. ${ }^{6}{ }^{7}$ There is also growing concern about the vulnerability of Roma to HIV/AIDS, sexually transmitted diseases, and other reproductive health problems. ${ }^{4}$ Studies with community samples of young Roma men in Bulgaria have shown high rates of unprotected sexual intercourse, frequent multiple sexual partnerships with both women and men, low levels of condom use, and prevalent sexually transmitted diseases. ${ }^{9-11}$ In recent trials undertaken with young men who have sex with men in Russia and Bulgaria, ${ }^{12}{ }^{13}$ we found that an HIV prevention approach that trains social network leaders to function as risk reduction counsellors and advocates significantly reduced levels of high risk sexual practices among others in the social networks. We conducted a randomised controlled trial of a social network-level HIV prevention in a Roma settlement in Sofia, Bulgaria.

\section{Methods}

\section{Setting, social network recruitment, and participants}

Our trial was conducted in 2003-5 in the Fakulteta settlement, which has about 35000 residents and is one of Bulgaria's three largest and poorest Roma communities. Field teams with two members conducted systematic ethnographic observations throughout meeting places, including street corners, cafes, disco clubs, and back yards. Because teams were composed of staff who had long carried out Roma community development service programmes, they were not regarded with suspicion. Field staff looked for the presence of "social circles." ${ }^{14}$ When researchers agreed that a group constituted a social circle, they decided who was the circle's social and affective centre of attention, termed the "index." Indexes were the entry points for accessing and recruiting social networks.

Each index was approached and privately interviewed. After a brief description of the study, he was asked to indicate the first names of the friends with whom he most liked to spend time, talk to, and trusted. These people were defined as members of the index's social network and were contacted and recruited for

This is the abridged version of an article that was posted on bmi.com on 13 October 2006: http://bmi.com/cgi/doi/10.1136/ bmj.38992.478299.55 
participation. Of the 55 networks (representing 303 individuals) approached, 52 networks (representing 286 individuals, all men) participated. This constitutes all people named as network members by the 52 indexes. Networks were enrolled in two recruitment waves ( 26 networks per wave) separated by a 12 month period. This allowed us to assess the entire sample at points close to scheduled follow-up dates.

The mean size of social networks including the index was 5.3 men (range 3-9). Participants' mean age was 19.7 years, $68 \%(\mathrm{n}=194)$ were single, $92 \%$ $(\mathrm{n}=263)$ did not have steady employment, mean education level was 6.3 years, but only $14 \%(n=40)$ still attended school.

\section{Assessments}

Each participant provided informed consent and attended one baseline assessment session lasting about 60 minutes in a neighbourhood research office. Participants received an incentive of $\$ 8$ (about $£ 4$ or $€ 6)$ for attending each assessment session.

At the assessment session participants completed scales measuring five psychosocial characteristics related to AIDS adapted from previous research [full details on bmj.com]. ${ }^{9} 101315$ Because many men could not read, all measures were read aloud. The assessment determined the respondent's number of female and male sexual partners and history of giving or receiving money or valuables for sex. Participants also indicated on how many days during the past three months they injected any drug or used alcohol or other substances.

Each participant was presented with a list of the names of all other members of the same network and indicated who, from that list, he most and least preferred in five domains (such as spending time together, trusted for advice, discussion of important matters). A sociometric analysis program ${ }^{16}$ determined which network member received most positive (and least negative) citations from all other members of the same network. We calculated a "social status indicator" score for each member in each domain. The network member with the highest score across leadership areas was designated as its leader. ${ }^{17}$

We tested urine samples for gonorrhoea and chlamydia and blood samples for syphilis (full details on bmj.com). At the same session, each participant received about 15 minutes of individual counselling on HIV risk reduction. This provided information about HIV/AIDS, steps to reduce risk, and local resources for HIV testing. All participants received free condoms, which were also available continuously at a neighbourhood community centre. We used a randomisation table to assign the 52 social networks in equal numbers to intervention and control group conditions within each recruitment wave.

\section{Social network intervention procedures}

In the intervention group, leaders of each network received training on how to counsel and advise other members of the network on reducing HIV risk behaviour. Leaders attended small group training sessions each week for five weeks followed by booster sessions every two weeks and then every two months. Two facilitators led group sessions, which lasted about two hours and included six or seven leaders. Leaders received \$6 for attending each group. Sessions followed a detailed intervention manual (full details on bmj.com).

\section{Follow-up}

Participants completed HIV risk assessments three months and 12 months after the interventions group's final training session. All psychosocial scales related to AIDS, the interview to assess sexual risk, and tests and treatment for sexually transmitted diseases were the same as at baseline.

\section{Statistical methods}

We assessed the effects of the intervention by examining changes in reported sexual risk behaviour and on the psychosocial scales between baseline and each follow-up point. We analysed dichotomous outcome variables in a logistic regression model and calculated incidence of sexually transmitted diseases as the number of follow-up visits when participants were diagnosed with a new infection.

For our primary outcome of participants' reports of having any unprotected intercourse during the past three months, we calculated that the 52 retained networks (with 26 networks per group, median of five members per network, and observed intraclass correlation coefficient range of 0.003 to 0.08 for the primary outcome among members of the same network) would have a power of 0.73 to 0.83 for detecting a $15 \%$ difference in prevalence of risk behaviour across the two groups.

Mixed effects linear regression and logistic regression analyses examined comparability of the intervention and control groups at baseline and tested the significance of the social network intervention at each follow-up. There were no baseline differences between groups. Because all members of each social network were randomised together as an intact group rather than individually, responses among members of the same social network were correlated. To control for the non-independence of responses among members of the same network, we incorporated the network as a random effect factor in each model. ${ }^{18}$ Because networks were recruited in two waves, we included effects for wave and the wave by group interaction as fixed factors in each model. We used SPSS (version 13.0; SPSS, Chicago, IL) and SAS macros Glimmix (version 8.0; SAS Institute, Cary, NC).

\section{Results}

Participants' background sexual risk behaviour Men in the sample at baseline had a lifetime mean of 27.5 (median 13) sexual partners including a mean of 7.1 (median 4) in the past year and 3.2 (median 2) in the past three months. Almost all men had female partners and described themselves as heterosexual, but many reported having sex with men in their lifetime $(59 \%, \mathrm{n}=169)$, the past year $(35 \%, \mathrm{n}=100)$, and the past three months $(20 \%, \mathrm{n}=58)$. Of the 286 men in the sample, $170(59 \%)$ had multiple sexual partners during the past three months at baseline and $191(67 \%)$ had sex with casual partners. Eight men (28\%) said they had paid for sex and 110 (39\%) reported being paid for sex during their lifetimes. Most participants $(89 \%$, $\mathrm{n}=253)$ reported using alcohol but only $10(4 \%)$ had injected drugs during the past three months.

\section{Verification of conversations}

Intervention group leaders attended a mean of 8.1 of the nine intervention sessions. Their monitoring grids
Department of Dermatology and Venereology Medical University of Sofia, Sofia 1606,

Bulgaria

Elena Petrova

senior assistant professor of dermatology and venereology

Department of Dermatology and Venereology, Military Medical Academy, Sofia 1606, Bulgaria

Borislav Dimitrov assistant professor of dermatology and venereology

Correspondence to: J A Kelly kdemming@mcw.edu 
showed that conversations related to AIDS took place with a given network member on a mean of 3.8 of the five weeks during the main intervention training period. These conversations were independently corroborated by group members' reports of more frequent $(\mathrm{P}=0.02)$ conversations about AIDS with close friends, from a mean of 2.5 during the three months before baseline to 6.8 at three month follow-up (compared with 1.2 to 2.2 for the control group). Conversations about safer sex also increased more $(\mathrm{P}=0.007)$ in intervention networks (from 5.5 to 11.8 ) than control networks (6.1 to 6.6 ), verifying that network leaders delivered the planned conversations.

\section{Primary and secondary behavioural outcomes}

The table shows findings at baseline and follow-up for reported sexual risk behaviour during the three months before each assessment point. There was a significant reduction ( $\mathrm{P}=0.01)$ between baseline and the 12 month follow-up in the prevalence of unprotected intercourse reported by men in the intervention group compared with the control group. Over two thirds of men had casual partners. As the table shows, the prevalence of unprotected intercourse reported with casual partners declined in networks in the intervention group from $60 \%(\mathrm{n}=78)$ at baseline to $28 \%$ $(\mathrm{n}=33)$ at three months and 29\% $(\mathrm{n}=35)$ at 12 months. These reductions were significantly greater than those found in control networks $(\mathrm{P}=0.02$ and $\mathrm{P}=0.009$, respectively). The values shown in the table for the intervention group include network leaders. When we repeated the analyses excluding network leaders we found similar values, indicating that improvements were among members and not accounted for only by change in the leader.

The table also shows reported change over time for secondary behavioural outcomes. These patterns paralleled those found for the primary outcomes.

\section{Psychosocial scale secondary outcomes}

Relative to the control group, men in the intervention group significantly increased in their knowledge of risk of AIDS $(\mathrm{P}<0.001)$, positive attitudes towards condoms $(P=0.005)$, and strength of intentions to reduce risk behaviours $(\mathrm{P}=0.02)$ from baseline to three months. These differences were more pronounced at 12 months.

\section{Corroborative trends in incidence of sexually transmitted diseases}

Because all sexually transmitted diseases were treated at baseline, positive results later represent incident infections. By 12 months, 18 (14\%) men in the control group and $11(8 \%)$ in the intervention group had contracted gonorrhoea $(\mathrm{P}=0.09)$, and three men $(2 \%)$ in the control group and one in the intervention group had contracted syphilis. ${ }^{19}$ The incidence of chlamydia at follow-up was similar in both groups $(11 \%(\mathrm{n}=14) v$ $12 \%(n=16))$.

\section{Discussion}

Few randomised trials on interventions for HIV prevention have been undertaken in former socialist countries of eastern Europe, even though disease rates are rising and primary prevention efforts for HIV in

Changes in HIV risk characteristics for intervention and control groups from baseline to three and 12 month follow-up. Figures are percentages (numbers) of participants, unless stated otherwise

\begin{tabular}{|c|c|c|c|c|c|c|c|c|}
\hline \multirow[b]{2}{*}{ Variable } & \multicolumn{2}{|c|}{ Baseline } & \multicolumn{3}{|c|}{ Three months } & \multicolumn{3}{|c|}{12 months } \\
\hline & $\begin{array}{c}\text { Intervention } \\
(\mathrm{n}=145)^{\star}\end{array}$ & $\begin{array}{l}\text { Control } \\
(n=137)^{\star}\end{array}$ & $\begin{array}{c}\text { Intervention } \\
(\mathrm{n}=141)\end{array}$ & $\begin{array}{l}\text { Control } \\
(n=135)\end{array}$ & $\begin{array}{c}\mathbf{P} \\
\text { value }\end{array}$ & $\begin{array}{l}\text { Intervention } \\
(\mathrm{n}=143)\end{array}$ & $\begin{array}{l}\text { Control } \\
(n=132)\end{array}$ & $\begin{array}{c}P \\
\text { value }\end{array}$ \\
\hline \multicolumn{9}{|c|}{ Primary behavioural outcomes-prevalence of reported unprotected intercourse in past 3 months } \\
\hline Unprotected intercourse & $81 \%(118)$ & $80 \%(109)$ & $65 \%(92)$ & $75 \%(101)$ & $>0.10$ & $71 \%(102)$ & $86 \%(113)$ & 0.01 \\
\hline $\begin{array}{l}\text { Unprotected intercourse with } \\
\text { casual partners } \ddagger\end{array}$ & $60 \%(78)$ & $54 \%(68)$ & $28 \%(33)$ & $42 \%(47)$ & 0.02 & $29 \%(35)$ & $47 \%(53)$ & 0.009 \\
\hline \multicolumn{9}{|c|}{ Secondary sexual behavioural outcomes in past 3 months } \\
\hline $\begin{array}{l}\text { Unprotected vaginal intercourse } \\
\text { with }>1 \text { partner }\end{array}$ & $32 \%(46)$ & $30 \%(41)$ & $15 \%(21)$ & $26 \%(35)$ & 0.03 & $15 \%(22)$ & $29 \%(38)$ & 0.01 \\
\hline $\begin{array}{l}\text { Unprotected intercourse with } \\
\text { multiple casual partners }\end{array}$ & $43 \%(56)$ & $39 \%(49)$ & $16 \%(19)$ & $29 \%(32)$ & 0.03 & $13 \%(16)$ & $26 \%(29)$ & 0.01 \\
\hline $\begin{array}{l}\text { Mean }(\mathrm{SD}) \% \text { of reported } \\
\text { intercourse with condoms } \\
\text { with casual partners }\end{array}$ & $59.3(42.6)$ & $58.7(43.5)$ & $81.0(35.6)$ & $71.1(39.8)$ & $>0.10$ & $84.0(30.9)$ & $68.4(41.4)$ & 0.08 \\
\hline $\begin{array}{l}\text { Reduced rates of unprotected } \\
\text { intercourse with casual } \\
\text { partners at follow-up } \neq\end{array}$ & - & - & $85 \%(98)$ & $74 \%(83)$ & 0.10 & $85 \%(105)$ & $70 \%(78)$ & 0.007 \\
\hline $\begin{array}{l}\text { Unprotected vaginal intercourse } \\
\text { with casual partnersł }\end{array}$ & $51 \%(66)$ & $43 \%(54)$ & $26 \%(30)$ & $37 \%(41)$ & 0.08 & $28 \%(34)$ & $40 \%(45)$ & 0.07 \\
\hline $\begin{array}{l}\text { Unprotected anal intercourse } \\
\text { with casual partnersł }\end{array}$ & $42 \%(54)$ & $38 \%(48)$ & $17 \%(20)$ & $21 \%(24)$ & $>0.10$ & $11 \%(14)$ & $26 \%(29)$ & 0.01 \\
\hline \multicolumn{9}{|c|}{ Secondary psychosocial scale outcomes (mean (SD) score on scale) } \\
\hline Knowledge scale of risk of AIDS & $8.8(2.5)$ & $9.4(2.4)$ & $11.5(2.9)$ & $10.8(2.5)$ & $<0.001$ & $12.0(2.4)$ & $10.7(2.6)$ & $<0.001$ \\
\hline Safer sex peer norms & $8.2(3.5)$ & $7.7(3.4)$ & $9.4(3.4)$ & $8.0(3.6)$ & 0.07 & $10.0(3.5)$ & $8.2(3.7)$ & 0.03 \\
\hline Attitudes toward condom use & $10.5(4.1)$ & $10.6(3.8)$ & $12.8(4.0)$ & $11.4(4.1)$ & 0.005 & $12.6(3.9)$ & $10.8(4.0)$ & 0.002 \\
\hline $\begin{array}{l}\text { Intentions to reduce risk } \\
\text { behaviour }\end{array}$ & $10.6(4.5)$ & $10.7(4.7)$ & $14.7(4.7)$ & $13.0(4.9)$ & 0.02 & $14.6(4.7)$ & $12.5(5.2)$ & 0.007 \\
\hline Risk reduction self efficacy & $11.1(3.7)$ & $11.3(3.6)$ & $13.4(3.8)$ & $12.8(3.9)$ & 0.06 & $14.3(3.4)$ & $12.9(3.5)$ & 0.002 \\
\hline
\end{tabular}

${ }^{*}$ Excludes one participant in intervention group and three in control group who did not complete follow-up assessment at either time.

†Based on mixed liner models or logistic regression models for individuals nested within social networks. All reductions shown are from baseline levels. For condom use, analyses treated sexual abstainers as $100 \%$ condom users.

¥At baseline 255 participants (130 in intervention group and 125 controls) had $\geq 1$ casual partners in past 3 months. At 3 month follow-up, 228 participants (116 in intervention group and 112 controls) had $\geq 1$ casual partners in past 3 months. At 12 month follow-up, 235 participants (123 in intervention group and 112 controls) had $\geq 1$ casual partners in past 3 months. 
the region are urgently needed. We are unaware of previous scientific research evaluating the impact of health promotion interventions of any kind for Roma, a large minority population with severe pervasive social and public health needs. We chose the social network intervention model used in this study because of its relevance in cultures where vulnerable populations may distrust outside authorities but find advice and recommendations coming from personally known network leaders to carry credibility and influence.

We found that the social network intervention had a positive impact on reported sexual risk practices relative to a control condition in which participants received standard individual counselling on risk reduction, a traditional public health standard of care. Our primary outcomes were participants' reported sexual behaviour during the three months before each assessment, and we found change across numerous indicators of risk. The magnitude of effects was strongest among men who had casual partners, suggesting that benefits of the intervention were greatest among those who are at highest risk. Behavioural interventions typically show a weakening or decay in initial effects over time. By contrast, our data reflected greater robustness of changes reported at 12 months than at three months. This is heartening and consistent with patterns that would be expected if the norms of one's close social network changed over time to support the strengthening and maintenance of safer behaviour.

Confidence in the validity of participants' self reported change in sexual behaviour is strengthened by trends for a reduction in incidence of biologically assessed gonorrhoea during follow-up for men in the intervention group. Although the absolute number of newly diagnosed sexually transmitted diseases was modest, the almost twofold higher incidence of gonorrhoea found in the control group serves to validate the primary behavioural outcomes. In addition, significant change occurred between baseline and final follow-up for intervention versus control groups on knowledge related to AIDS, attitudes, and motivations to change. The fact that multiple measures all changed predictably, consistently, and in a well maintained fashion enhances confidence in the impact of the intervention.

\section{Study limitations}

This study was carried out in a single site, and risk behaviours in the sample may not be characteristic of other Roma communities or other populations. The study was powered for behavioural outcomes, and trends in incidence of sexually transmitted diseases must be viewed as corroborative. Studies with larger samples are needed to definitively test the direct effects of behavioural intervention on incidence of disease. Although measures were piloted, self reports of private behaviour are potentially subject to inaccuracy in recall or presentation bias. The internal consistency of several of the psychosocial scales was modest. None the less, we have shown that an HIV prevention model at the level of social networks can be effective when it is tailored to the cultural circumstances of a disadvantaged population vulnerable to serious social health problems and highly understudied in public health.

Contributors: See bmj.com.

Funding: Grants R01-MH64410 and P30-MH52776 from the US National Institute of Mental Health.

\section{What is already known on this topic}

Roma (Gypsies) are the largest ethnic minority group in eastern Europe, and social health problems related to disadvantage are pervasive and severe

Levels of sexual risk behaviours are high among Roma men

The effects of interventions for HIV prevention in Roma men have not been systematically studied

\section{What this study adds}

After identifying, training, and engaging the leaders of Roma men's social networks to endorse and counsel their own network members in HIV prevention, prevalence of unprotected intercourse reduced over a 12 month follow up

Effects were especially pronounced in risk behaviour with casual partners

Competing interests: None declared.

Ethical approval: Institutional review board of the Medical College of Wisconsin and ethics committee of the Health and Social Development Foundation in Sofia, Bulgaria.

1 Liegois JP. Roma, Gypsies, and travelers. Strasbourg, France: Council of Europe, 1994.

Tomova I. Gypsies of the transition period. Sofia, Bulgaria: IMIR Publications, 1995.

3 UNDP. National human development report. Geneva: United Nations Development Program, 2003.

4 UNDP. Social assessment of Roma and HIV/AIDS in Central and Eastern Europe. Bucharest, Romania: United Nations Development Program/ Romania Country Office and Center for Health Policies and Services, 2003.

5 UNDP. Faces of poverty, faces of hope: vulnerability profiles for decade of Roma inclusion countries. Bratislava, Slovakia: UN Development Program, 2005.

National Institute of Statistics. Survey on health status of the Bulgarian population. Sofia, Bulgaria: National Institute of Statistics, 2001.

7 Timeline of Romani history. Patrin Web Journal www.geocities.com/ Timeline of Romani history. Patrin Web Jour
$\sim$ patrin/timeline.htm (accessed 11 Sept 2006).

$\sim$ patrin/timeline.htm (accessed 11 Sept 2006).
World Bank. HIV/AIDS in Southeastern Europe: case studies from Bulgaria, Croatia, and Romania. Washington, DC: World Bank, 2003.

9 Kabakchieva E, Amirkhanian YA, Kelly JA, McAuliffe TL, Vassileva S. High levels of sexual HIV/STD risk behavior among Roma (Gypsy) men in Bulgaria: patterns and predictors of risk in a representative community sample. Int J STD AIDS 2002;13:184-91.

10 Kabakchieva E, Vassileva S, Kelly JA, Amirkhanian YA, DiFranceisco WJ, McAuliffe TL, et al. HIV risk behavior patterns, predictors, and STD prevalence in the social networks of young Roma (Gypsy) men in Sofia, Bulgaria. Sex Trans Dis 2006;33:485-90.

11 Kelly JA, Amirkhanian YA, Kabakchieva E, Csepe P, Seal DW, Antonova $\mathrm{R}$, et al. Gender roles and HIV sexual risk vulnerability of Roma (Gypsy) men and women in Bulgaria and Hungary: an ethnographic study. AIDS Care 2004;16:231-45.

12 Amirkhanian YA, Kelly JA, Kabakchieva E, McAuliffe TL, Vassileva S. Evaluation of a social network HIV prevention intervention program for young men who have sex with men in Russia and Bulgaria. AIDS Educ Prev 2003;15:205-21.

13 Amirkhanian YA, Kelly JA, Kabakchieva E, Kirsanova AV, Vassileva S, Takacs J, et al. A randomized social network HIV prevention trial with young men who have sex with men in Russia and Bulgaria. AIDS 2005;19:1897-905.

14 Kadushin C. The friends and supporters of psychotherapy: on social circles in urban life. Am Soc Rev 1966;31:786-802.

15 Amirkhanian YA, Kelly JA, Kukharsky A, Dyatlov R, Granskaya J, Borodkina $\mathrm{O}$, et al. Predictors of AIDS risk behavior among Russian men who have sex with men: an emerging epidemic. AIDS 2001;15:407-12.

16 Sociometry Pro [computer program]. Version 2.1. Moscow: LeDis Group, 2003. www.sociometry.ru/eng/index.php (accessed 24 Nov 2005).

17 Amirkhanian YA, Kelly JA, McAuliffe TL. Identifying, recruiting, and assessing social networks at high risk for HIV/AIDS: methodology, practice, and a case study in St Petersburg, Russia. AIDS Care 2005;17:58-75.

18 Murray DM. Design and analysis of group randomized trials. New York: Oxford University Press, 1998.

19 UNAIDS. Fact sheet: HIV/AIDS in the newly independent states. Geneva: UNAIDS, 2002.

(Accepted 20 September 2006)

doi $10.1136 /$ bmj.38992.478299.55 